\title{
Application of Key Construction Techniques in Heating, Ventilation and Air-conditioning Engineering
}

\author{
Kuang Heng, a \\ ${ }^{1}$ CCTEG Chongqing Engineering Co., Ltd. Chongqing 400042, China \\ akuanghengcq@126.com
}

Keywords: heating, ventilation and air-conditioning; construction techniques; quality control; air-conditioning engineering

\begin{abstract}
In recent years, the economic level and people's living standard of our country have greatly improved, and higher requirements have been put forward for construction engineering. In order to give full play to the function of construction engineering, it is necessary to set up a variety of infrastructure, especially heating, ventilation and air-conditioning engineering, which plays an important role in improving the living environment. In this paper, the key technology of heating, ventilation and air-conditioning construction is studied. People have a new understanding of the quality of life, and pay more attention to comfort, so they have higher requirements for the function of architecture. Heating, ventilation and air-conditioning are important aspects of function improvement in construction. The construction of heating and ventilation project is mainly composed of heating and ventilation system and air-conditioning system, which are complicated in the construction of the project, and increase the difficulty of the technical construction requirements to a certain extent. The structure of heating, ventilation and air-conditioning projects is complex and the amount of construction is large. If the capital, technology and qualification of the construction units cannot reach a certain standard, then the construction quality will cannot be guaranteed. Therefore, this paper focuses on the heating, ventilation and air-conditioning construction technology.
\end{abstract}

New types of buildings and new functions have put forward higher requirements for the quality and innovation of building equipment, so HVAC has become an indispensable facility in modern buildings. Large quantities of engineering and many quality control points characterize HVAC projects. The construction of HVAC projects inevitably intersects with other specialties such as architecture, structure, decoration, water supply and drainage, electricity, intelligent building, etc. The construction management of HVAC project can improve the quality of the project and prevent common quality problems.

\section{The Key Technology of Heating, Ventilation, and Air-conditioning Engineering}

Determining the proper indoor temperature is the basic requirement of the scientific and suitable heating and ventilation system after the installation and operation of the air conditioning system. Only fixed indoor temperature values selected throughout the year. The applicable range is a small number of industrial air conditioners with special requirements. Most air conditioning systems will consume more heat energy when they adjust the temperature to a slightly higher temperature in winter. The same goes for the same. Lowering the temperature in summer also consumes a lot of energy. Constant room temperature is not only a good experience in comfort, but also a waste of energy. It is necessary to set up the heating system based on the actual indoor temperature requirements.

\subsection{Heating and ventilation system}

Green ecosystem is the development trend of architecture. This is also applicable to the installation of air conditioning systems, the general selection of energy saving air conditioning 
systems to reduce energy consumption. VAV air conditioning systems used in buildings to achieve energy conservation and emission reduction, and can perform well. In addition, a better energy-saving way is reasonable planning and control of the number of pumps and the number of revolutions.

In general, the minimum fresh air volume in the air - conditioning system and the minimum fresh air volume in summer controlled within the minimum value. In general, the minimum fresh air volume in winter and summer of the air - conditioning system set by the sanitary requirement of the body, the amount of compensation of the local exhaust air ensured. In addition, there is no big influence on temperature, humidity, smell, and dust and so on in the process of setting the concentration of carbon dioxide. In addition, there is no big influence on dust and smell in the room. Besides, it is necessary to set the minimum fresh air quantity standard in the room.

\subsection{Key technology for installation of Air-conditioning equipment}

Preparations should do before the installation of the air conditioning equipment, leveling the ground and wall surface, laying out or retaining the pipeline for normal construction. In the installation, the parts should check to be prepared, whether the tools are, complete, the material is in conformity with the design manual and the construction drawings. Meanwhile, the installation of the air vent, the heat preservation construction, the sealing inspection of the hole, the finished product and the finished product should also be paid attention to. In the process of design and construction of heating and ventilation and air conditioning engineering, there are many factors affecting the design and construction. We should grasp the main aspects of the problems and improve the details.

\section{Key Technology of Tuners Installation and Construction}

The decorative construction drawings, heating, ventilation and air conditioning construction drawings should be reviewed, especially for the complicated smallpox lobby, multi-function hall, conference room, etc., and the decoration should be coordinated with the arranged fire sprinkler, lamps and tuners. Therefore, when installing the tuners of this kind of room, it is not advisable to open the tuners first, to finish the examination of the design and decoration drawings and to determine the location of the tuners before opening. The resistance and the noise of the return tuners are increased, the air pipe elbows are increased, the air supply volume reduced, and the normal use of the system is affected. Therefore, when adjusting the tuners, Supervisors must ensure air conditioning function as a prerequisite. Moreover, often by the decoration construction unit to carry on the opening to the overhaul hole and the tuners, in order to prevent the hole position, the size occurrence omission or the mistake, the heating ventilation and the air conditioning installment unit should provide the decoration drawing marked with the tuners position and the dimension to the decoration unit.

\subsection{Supervision support of installation of chilled pipe}

For example, the pipe in charge of a certain project is large in diameter and slightly vibrated. According to the engineering installation experience, the noise is found to be transmitted along the freezing supervisor, and the exit can generally reach $70 \mathrm{~dB} / \mathrm{a}$, and can be lowered to $50 \mathrm{~dB} /$ at 20 $\mathrm{m}$ away from the outlet. In addition, the slight vibration transmitted along the rigid conductor will be infinite. Through research and experiment, the improvement of rigid support is made, that is, adding spring shock absorb to the original rigid support, so that the vibration and noise can be effectively eliminated by the spring damper between floor slab and rigid support. Therefore, the proposal is relevant the construction enterprise, in the machine room supply and return water supervisor, the freezing water supervisor also uses this craft construction, eliminates the noise.

\subsection{Correct installation of air-conditioning and related equipment}

Whether air conditioning and related equipment installed will directly affect the quality of the project. In the installation process of air conditioner, the connection part of inlet and outlet pipe 
should seal, and the slope of condensate pipe should meet the drainage standard and requirement of air conditioner. During the installation of the silencer, the installation direction must be correct, the annular direction of the airflow should be accurately marked on the shell of the silencer, and the support and hanger should be set correctly separately. In the process of fan installation, the distance between the fan impeller and the shell needs to control reasonably to avoid touching each other in operation. During injection, all automatic air release valves and system valves cane opened so that the air in the pipeline can escape automatically, and at the same time, the fan discharge cock opened one by one. Close the cock until the water released. When the water injected into the inlet pressure gauge of the circulating pump 0.1MPa, the system water injection is suspended and stabilized for a period. The pressure gauge is stable and the system is finished.

\subsection{Key technology of thermal insulation construction}

The key of heating ventilation and air conditioning construction also includes heat preservation construction. If the quality of heat preservation process is not good, the system will cause condensate water leakage during operation, which will not only waste energy, but also destroy the normal operation of the system. The construction of water system is a difficult point for heating, ventilation and air conditioning and insulation. Under the requirements of supervisors, the construction party completes the heat preservation construction strictly according to the procedure before installing the roof keel and after the pipe pressure test is qualified. The quality problems are easy to occur in construction, such as the improper matching of mats or too large pores with pipes, the encompassed adhesion of mats and insulation materials, and the unqualified coverage of the insulation layer of valves, etc. The air supply and air conditioning pipeline have been behind after the completion of construction. Many wall and floor reserved holes, the installation unit often will not plug their own, once the plugging can not meet the requirements, will cause air leakage, can not carry out air exchange and exhaust gas, or lead to insufficient fresh air. Therefore, to prevent omissions, supervision personnel should supervise the relevant units, timely plugging.

\section{Main Points of Construction Technology for Heating, Ventilation and Air-conditioning Engineering}

The production and installation of air duct is also one of the basic works in heating, ventilation and air conditioning engineering. At present, the most commonly used method for the production of air ducts is the combination of mechanical and manual production. The construction technicians should strictly follow the design drawing before making the air pipe. In the concrete installation project, the best coordination scheme should be determined by taking into account the cross construction of electric line, water supply and drainage pipeline, environmental control line and so on. After drawing the drawings of heating, ventilation and air conditioning installation, make a technical foundation for the construction personnel on site. When making air duct, you can also carry out support, suspension, flange, and other related projects. In addition, 10-20m the air pipe of the pipe section connected on the ground and the air pipe hoisting mainly uses manual or electric hoist, channel steel and so on to reach the design height Zhang $\mathrm{Z} \mathrm{h}$. Then operates the hanger to carry on the fixed treatment, at the same time the lift ladder made a good reserve. If air ducts need to pass through the wall or floor, they should be welded with thin steel plates larger than $2 \mathrm{~mm}$ thickness and be separated from the wall or floor by more than $200 \mathrm{~mm}$. In addition, the use of fireproof materials to tie air pipe, to ensure the safe use of air pipes.

\subsection{Air system installation}

Air system is one of the important contents of ventilation and air conditioning engineering, and it is an important way to avoid noise. In the specific installation process, we need to control the construction quality. At the same time, the system equipment noise processing technology should also strictly follow the relevant technical procedures. Air pipe hanger had better use rubber damping pad, to protect the duct from vibration noise.

Common problems and countermeasures in the design and commissioning of air conditioning 
system of heat supply fan. If condensation or dripping caused by breakage or leakage of insulation layer can exclude, it is very likely that the overflowing and dripping of air conditioning equipment can caused by too long condensing pipe or insufficient drainage slope. Therefore, the condensing water should be discharged as close as possible in order to avoid the stagnant water on the slope of the condensate pipe, and the water seal should be set up according to the negative pressure of the machine in order to make the discharge of condensate water unblocked. When designing, air conditioning ventilation system should avoid sudden increase of wind pressure drop caused by avoiding beam or other pipeline. If this situation is inevitable, the air pressure of the air conditioning equipment should adjusted again to avoid the reduction of air supply volume due to insufficient air pressure and the lower air supply temperature than the air supply set the room dew point temperature, the appearance of the tuners dew drip.

\subsection{Control measures of construction quality}

Due to the problems of materials and equipment in the design process of heating, ventilation and air conditioning engineering, the choice and application of materials and equipment should placed in a prominent position in building construction enterprises to strictly control the quality of equipment and materials. It is a good opportunity for construction units to set up their own image and strengthen the competitiveness of enterprises. Each building construction unit should specifically establish a professional installation team that has always had high quality and high technology and regularly train its staff on technical and theoretical knowledge to enable them to acquire the most advanced relevant technologies and to integrate them into the following areas: --Fully apply to the construction process. Especially in dealing with the water cycle of air conditioning, staff must take into account the factors that easily affect the air conditioning refrigeration system to do a good cleaning work to ensure that the projects carried out smoothly.

\section{Summary}

In order to improve the quality of buildings and promote the development of economy, we must do our best to solve the problems existing in the construction technology of heating, ventilation and air conditioning in building construction. Therefore, we must use appropriate materials, make use of scientific and reasonable construction techniques, and let the internal structure of air conditioning coordinate to provide a warm and comfortable living environment for the occupants. Improve the satisfaction of the occupants, promote the residents and the building developers to establish a good relationship, and ultimately promote the development of the construction industry, and promote economic progress. Through the effective construction technology, control can greatly enhance the heating ventilation and air conditioning Construction quality, effectively improve indoor living environment, and provide people with more comfortable living conditions.

\section{References}

[1] Zhang W Y. Heating, ventilation and Air-conditioning Installation Technology [J]. Exploration: 232-234.

[2] Yang D Q. Discussion on the key problems of heating, ventilation and Air-conditioning Engineering Construction Technology [J]. A study on the Theory of City Construction (Electronic version: 65: 56).

[3] Zhang L J. Study on the Common problems in the Construction of ventilation and Air-Conditioning Engineering in High-rise buildings [J]. Science and Technology Information, 2012 / 8.

[4] Wang Z Q. Discussion on Construction Technology and quality Control of ventilation and Air conditioning installation Project [J]. Doors and windows, 2012 pieces).

[5] J H. On the installation technology of heating, ventilation and air conditioning in modern 
building engineering [J]. Heilongjiang science and technology letter Z, 2013 (21): 111-112.

[6] Glueck B. Simplified model for exploring dynamic reactions during the operation fornetwork sto rage [J]. Firmware International, 1983,12(3): 139-151.

[7] Oeljeklaus G. Short-time heat storage in district heating networks[J]. Fernwaerme International, 1989, 18(4): 362-364.

[8] Shi Z Y. Operation Regulation and Control of heating system [M]. Tsinghua University Press.

[9] Fu Lin. Study on peak-shaving operation mode of cogeneration power system [D]. Ph. D. thesis of Tsinghua University. Beijing: Tsinghua University. 